\title{
GEOTECNOLOGIAS APLICADAS AO USO E OCUPAÇÃO DA TERRA NA PARTE COMPONENTE BACIA HIDROGRAFICA DO RIO CARRO QUEIMADO - MS - BRASIL
}

\section{Adalto Moreira Braz'1}

\section{Patrícia Helena Mirandola Garcia²}

\section{Renan de Almeida Silva ${ }^{3}$}

Resumo: Este trabalho é resultado de uma pesquisa de um ano, correspondente ao relatório final entregue conforme exigência do $\mathrm{CNPq}$ à bolsistas de iniciação científica. A pesquisa aconteceu entre os anos de 2011/2012 e teve por objetivo realizar uma análise multitemporal a partir da elaboração e análise de mapas de uso e ocupação da terra para fins de planejamento na bacia hidrográfica do rio Carro Queimado (BHRCQ), a partir de geotecnologias disponíveis, estas que atualmente permitem retratar o ambiente em questão, de forma muito próxima da realidade encontrada no campo, fornecendo dados capazes de subsidiarem uma posterior decisão no planejamento da área. O Rio Carro Queimado Localiza-se no município de Três Lagoas - MS com uma área de aproximadamente $81,62 \mathrm{Km}^{2}$. Para este trabalho foram usadas cartas topográficas, imagens de radar da missão Shuttle Radar Topography Mission (SRTM), imagem Landsat 5 sensor TM dos anos de 2000 e 2011 e o SIG Spring® 5.2.

Palavras-Chave: Geotecnologias, Uso da Terra, Bacia Hidrográfica.

${ }^{1}$ Acadêmico do curso de Geografia (Bahcarelado) da UFMS; e-mail: adaltobraz.geografia@gmail.com 2Professora Dra. do programa de Pós-Graduação em Geografia da UFMS; e-mail: patriciaufmsgeografia@gmail.com

${ }^{3}$ Acadêmico do curso de Geografia (Licenciatura) da UFMS; e-mail: geo.renanalmeida@gmail.com 
Os estudos ambientais realizados com o auxílio de geotecnologias, como o sensoriamento remoto, GPS, SIG e geoprocessamento, GPS permitem que estudos sejam feitos em laboratórios a partir de imagens de satélite da área de estudo desejada, utilizando técnicas de fotointerpretação.

Interpretar as imagens de satélites é identificar os objetos nelas compostos, e esta dependerá sempre do conhecimento do interprete em sensoriamento remoto e da área de estudo, e quanto maior for este conhecimento mais informações serão extraídas (FLORENZANO, 2008).

O uso de geotecnologias para o mapeamento do uso e ocupação da terra tornou-se um importante procedimento para o planejamento de uma determinada área. $\mathrm{E}$ a partir destas ferramentas tornou-se fundamental o uso de um SIG neste trabalho (neste, o Spring), que tem a finalidade de analisar de forma integrada o ambiente. Este trabalho determina o uso e ocupação da terra com o propósito de identificar as mudanças ocorridas na área da bacia hidrográfica nos anos de 2000 e 2011. A expressão "uso da terra" pode ser entendida como a forma pela qual o espaço está sendo ocupado pelo homem (ROSA, 1992). Sendo assim, é essa técnica que nos permite considerar a forma como o espaço está sendo ocupado, se este é explorado de forma organizada e produtiva de acordo com sua região. Mapeamentos de uso e ocupação da terra são importantes no auxílio de um estudo ambiental, nos revelando dados mais atualizados sobre uma determinada área colaborando para identificação e localização dos agentes responsáveis pelas suas condições ambientais.

Processos naturais como erosão ocorre de forma natural, independente de ações antrópicas, mas quando o homem transforma o espaço tais processos podem se tornar violentos, trazendo conseqüências imediatas, refletindo o mau uso da terra. MIRANDOLA (2006) afirma que a erosão pode ser produto de vários problemas existentes, ligados ao uso e manejo inadequado dos recursos naturais.

Com informações de imagens de satélite, rápidas e econômicas (no caso de imagens que se encontram disponível para download como no site do INPE, por exemplo) temos uma forma de se fazer a análise do uso e ocupação da terra de um local, permitindo-nos realizar uma posterior exploração de forma organizada, que seja produtiva 
e um planejamento necessário, de acordo com as necessidades de cada região. Segundo MIRANDOLA (2006) para que haja a possibilidade de se efetivar uma proposta de Avaliação Ambiental, muitas etapas de pesquisa devem ser realizadas em uma determinada área, região, bacia, município ou qualquer outra forma de delimitação dos limites operacionais, buscando atender a vários objetivos, dentre eles os diagnósticos e prognósticos ambientais.

O presente trabalho apóia-se no enfoque sistêmico, considerando o ambiente como um sistema ambiental, baseado na perspectiva de Bertalanffy (1972), propondo o entendimento deste sistema ambiental, a partir da Teoria Geral dos Sistemas. Bertalanffy constata que para o ambiente ser entendido, esse não pode ser encarado como uma soma de suas partes, tende ser considerado as partes que compõem o sistema, para que se possa analisar o todo. Este sistema é compreendido, então, como Sistema, Subsistema e Parte componente.

\begin{abstract}
É necessário estudar não somente partes e processos isoladamente, mas também resolver os decisivos problemas encontrados na organização e na ordem que os unifica, resultante da interação dinâmica das partes, tornando o comportamento das partes diferente quando estudado isoladamente e quando tratado no todo (BERTALANFFY, 1972, p.53).
\end{abstract}

Sendo assim, a partir da análise da Teoria Geral dos Sistemas considera-se:

- Sistema: Bacia Hidrográfica do Rio Paraná

- Subsistema: Bacia Hidrográfica do Rio Sucuriú

- Parte componente: Bacia Hidrográfica do Rio Carro Queimado

Logo, a Bacia Hidrográfica do Rio Carro Queimado é uma parte componente do Subsistema Rio Sucuriú, que se enquadra dentro do Sistema Rio Paraná, segundo a Teoria Geral dos Sistemas. A BHRCQ está inserida no município de Três Lagoas/MS com uma área de aproximadamente $81,62 \mathrm{Km}^{2}$, entre as coordenadas geográficas longitude $51^{\circ}$ $44^{\prime} 42^{\prime \prime}$ a $51^{\circ} 51^{\prime} 59^{\prime \prime} \mathrm{O}$ e latitude $20^{\circ} 28^{\prime} 29^{\prime \prime}$ a $20^{\circ} 35^{\prime} 04^{\prime \prime} \mathrm{S}$, o município possui uma população de 101.791 mil habitantes, sendo a população urbana 97,069 mil habitantes e população rural 4.722 mil habitantes, e a densidade demográfica no município é de 9,97 $\mathrm{hab} / \mathrm{Km}^{2}$ (Censo IBGE, 2010). 


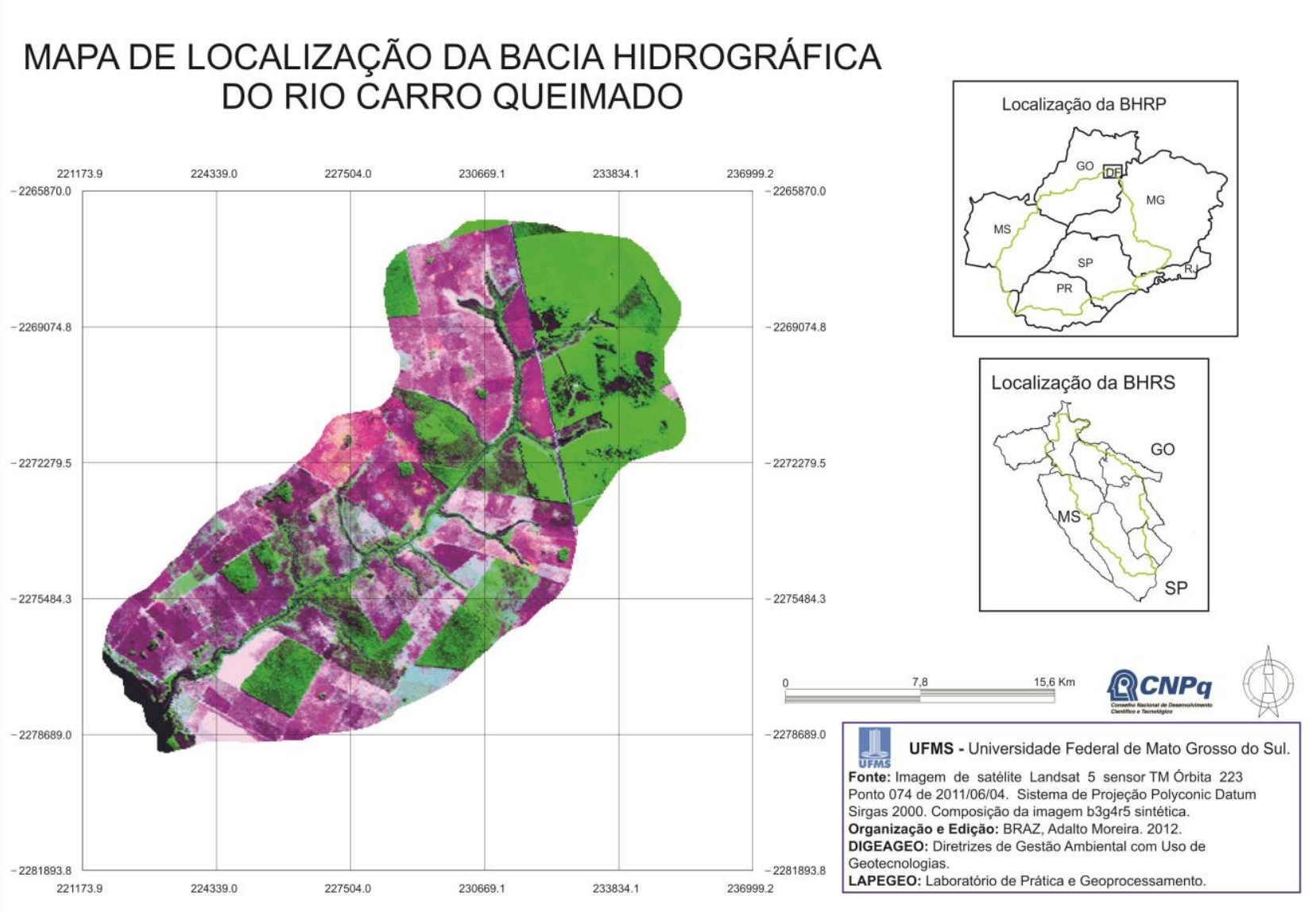

\section{METODOLOGIA}

Para este estudo utilizou-se imagens de satélite Landsat 5 sensor TM órbita 223 ponto 74, resolução espacial de 30 metros, dos anos 2000 (2000/07/07) e 2011 (2011/06/04) possibilitando um posterior mapeamento que contribuiu para uma análise multitemporal na área da bacia, afim de se caracterizar as mudanças do uso e ocupação da terra no decorrer destes anos dentro da delimitação da BHRCQ. As imagens foram primeiramente adquiridas no site do INPE (Instituto Nacional de Pesquisas Espaciais), disponíveis para download gratuitamente através do site www.dgi.inpe.br. Para o processamento das imagens foi utilizado o software Spring ${ }^{\circledR}$ 5.2. Os procedimentos utilizados basearam-se na aquisição manipulação e armazenamento dos dados da área de estudo que foram processados e transformados em informações referentes à BHRCQ. 
A primeira etapa dos procedimentos baseou-se na criação de um banco de dados para posteriormente se elaborar o projeto com a delimitação da área de estudo. Na segunda etapa foi realizado o georreferenciamento da imagem, após esse procedimento foi executado o contraste, com a finalidade de melhorar a qualidade da imagem e o mapeamento desta, cuja opção foi equalizar o histograma. A partir deste contraste foi feita a composição colorida da imagem, a qual possibilitou a classificação do uso e ocupação da terra.

A próxima etapa constituiu a realização das atividades de processamento das imagens, como: elaboração de contraste, segmentação e classificação, feita por região utilizando o classificador Bhattacharya com uma liminar de aceitação de $99,9 \%$ e similaridade de 10 e área 8 pixel.

O classificador Bhattacharya se aplica sobre o resultado do processo de segmentação, ou seja, classifica-se um conjunto de pixels, gerando áreas mais contínuas. (CORREIA et al 2007)

A partir da análise visual em laboratório foi realizada a checagem da área de estudo em campo em alguns pontos de dúvidas da imagem, podendo identificar com clareza as classes temáticas presentes nos pontos de dúvidas. Para a checagem de campo foram utilizados receptor GPS (Sistema de Posicionamento Global) Garmin modelo eTrex Vista $\AA$, para demarcar pontos de dúvidas encontrados na imagem, câmera digital para registros fotográficos, além de ferramentas de gabinete usadas para a manipulação destes dados, como o Corel Draw $12 \AA$, Microsoft Word®, Microsoft Excel® e o SIG (Sistema de Informações Geográficas) Spring, já mencionado aqui.

$\mathrm{Na}$ checagem de campo foi utilizada a Matriz de Leopold, com a finalidade de identificar os impactos ambientais na área da bacia. A Matriz de Leopold consiste em uma matriz para análise de impactos ambientais, na qual são quantificados os prováveis efeitos das atividades humanas sobre os vários aspectos do ambiente (conforme Leopold et al., 1971 apud CHRISTOFOLETTI, 1999). A matriz, elaborada por LEOPOLD et al (1971), no Serviço Geológico dos Estados Unidos, consiste em uma união de duas listas de verificação. Uma lista de ações ou de atividades mostrada horizontalmente, e uma lista que aparece na vertical, incluindo os 
componentes ambientais. A inclusão destas duas listas, formando a matriz tem a finalidade de auxiliar a identificação dos impactos ocorridos naquele determinado ambiente.

A matriz pode ser utilizada para medir e interpretar os impactos descrevendo-os em termos de magnitude e importância (P.e., numa escala de valores entre 1 e 10, onde 1 é a menor magnitude de importância e 10 a maior). Os valores podem ser acompanhados pelos sinais mais $(+)$ e menos (-) a fim de indicar se o impacto é benéfico ou adverso. (CHRISTOFOLETTI, 1999).

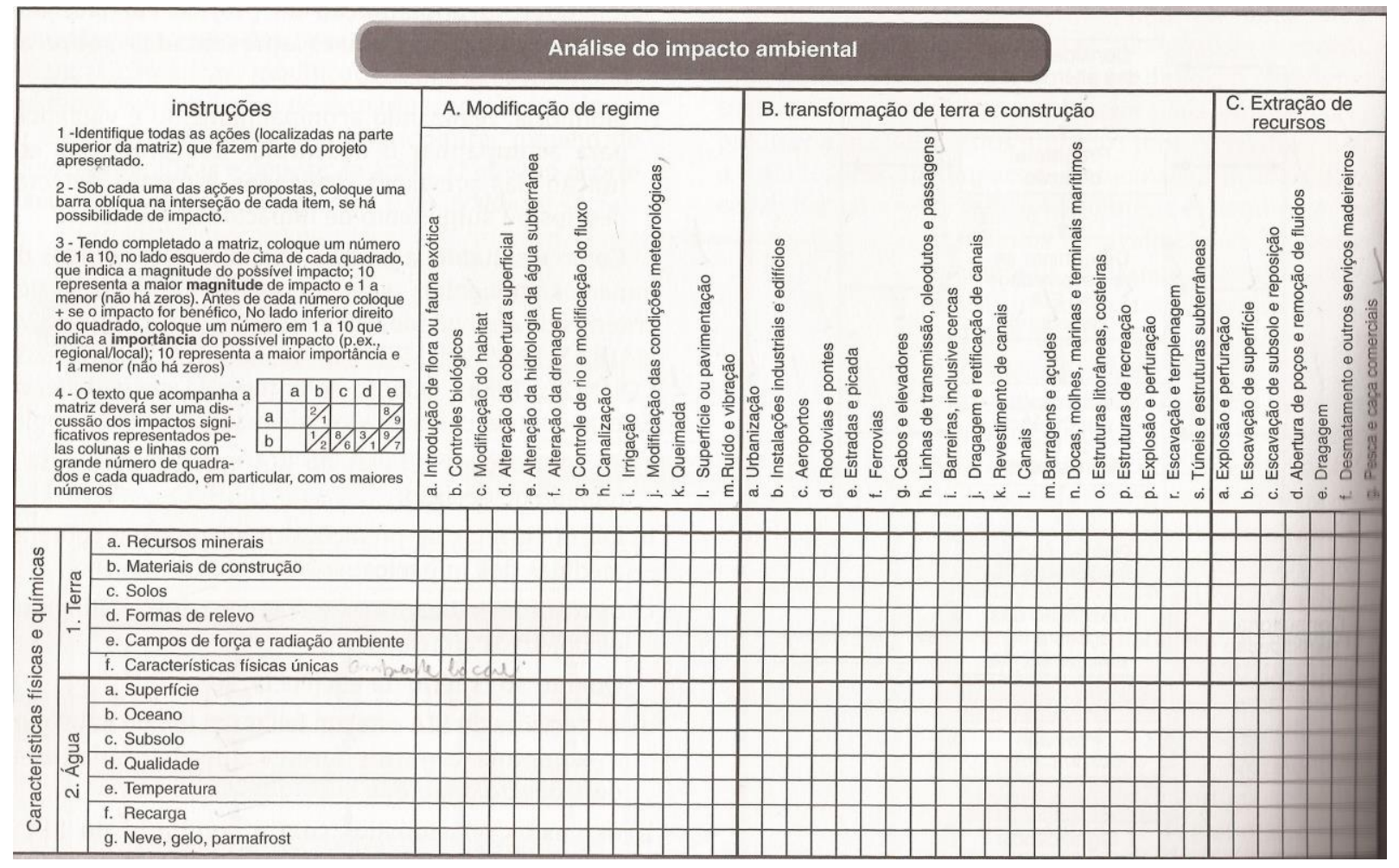

Quadro 01 - Parcela da matriz para análise de impactos ambientais, na qual são quantificados os prováveis efeitos das atividades humanas sobre os vários aspectos do ambiente (conforme Leopold et al., 1971 apud CHRISTOFOLETTI, 1999)

Para o uso da Matriz de Leopold neste trabalho, foi necessário que se fizessem algumas adaptações na matriz para melhor diagnóstico da área da bacia e conforme as necessidades para a checagem de campo. Acrescentou-se uma tabela para que fosse possível adicionar informações sobre a bacia hidrográfica, como, nome da bacia hidrográfica, localização, datas, coordenadas, altitude, precisão do GPS e algumas observações, caso necessário. 
Das modificações feitas na matriz para este trabalho, a principal consiste na mudança na forma de análise da matriz, que deixou de ser utilizada com intuito de identificação de impactos ambientais, passando a ser uma matriz de identificação de análise de alteração ambiental (Matriz de Análise Ambiental para Bacias Hidrográficas) (LAPEGEO, 2011. IZIPPATO, F. J.; MIRANDOLA, P. H.).

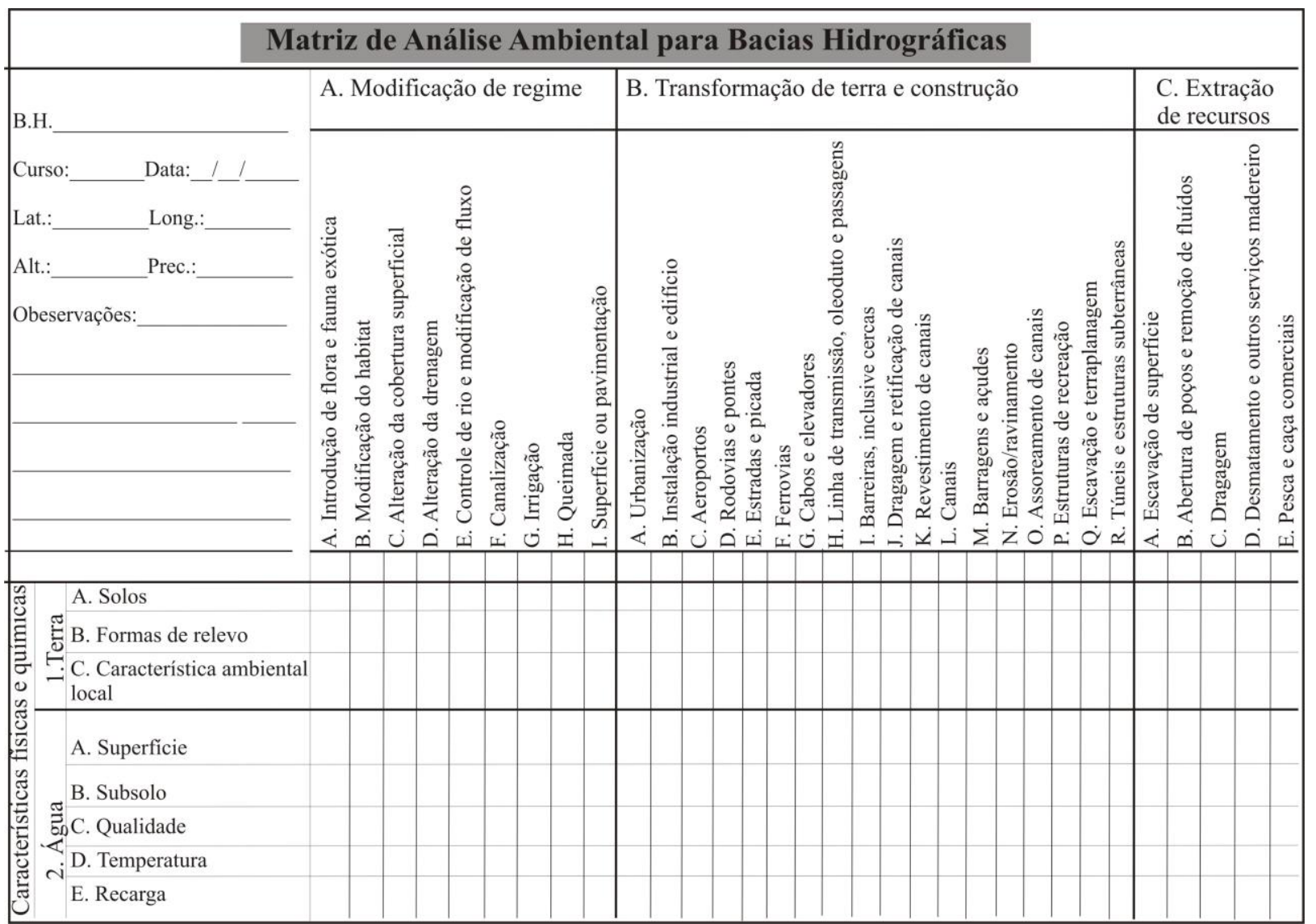

Quadro 02: Matriz de Análise Ambiental para Bacias Hidrográficas (conforme LAPEGEO, 2011. IZIPPATO, F. J.; MIRANDOLA, P. H

\section{RESULTADOS}

As imagens de satélite da área da BHRCQ permitem uma visualização geral do ambiente nos anos de 2000 e 2011. Permitindo-nos compreender a forma pela qual era feito o uso e ocupação da terra desta área no ano de 2000, e como é feito na atualidade, tornando possível de se realizar ações planejadas para o futuro do ambiente estudado. 
As quantificações apresentadas neste trabalho estão associadas às imagens de satélites da área da bacia estudada, utilizadas para a análise do uso e ocupação da terra, de forma multitemporal. Após o processamento digital da imagem de 2000 foram mapeadas 5 classes, sendo: Vegetação Natural Florestal, Vegetação Natural Campestre, Pastagem, Áreas Úmidas e Água Continental. Posteriormente, o outro ano analisado foi 2011, onde foram mapeadas 6 classes, sendo: Vegetação Natural Florestal, Vegetação Campestre, Pastagem, Silvicultura, Áreas Úmidas e Água Continental.

No ano de 2000 predominaram-se na área da BHRCQ as classes Pastagem e Vegetação Natural Campestre com $41 \%$ e $35 \%$, respectivamente, já que essas classes são tradicionalmente usadas como área de pecuária no estado de Mato Grosso do Sul que é tipicamente conhecido como um grande produtor de gados no Brasil. A classe Vegetação Natural Florestal apresentou 14\% (menos da metade da área de vegetação natural campestre), deixando claro que no ano de 2000 a área da bacia era voltado à pecuária, principal economia da região. Outras classes mapeadas foram Áreas úmidas, com $8 \%$, apresentando grande concentração próxima às áreas de nascente do rio, e Água, com $2 \%$.

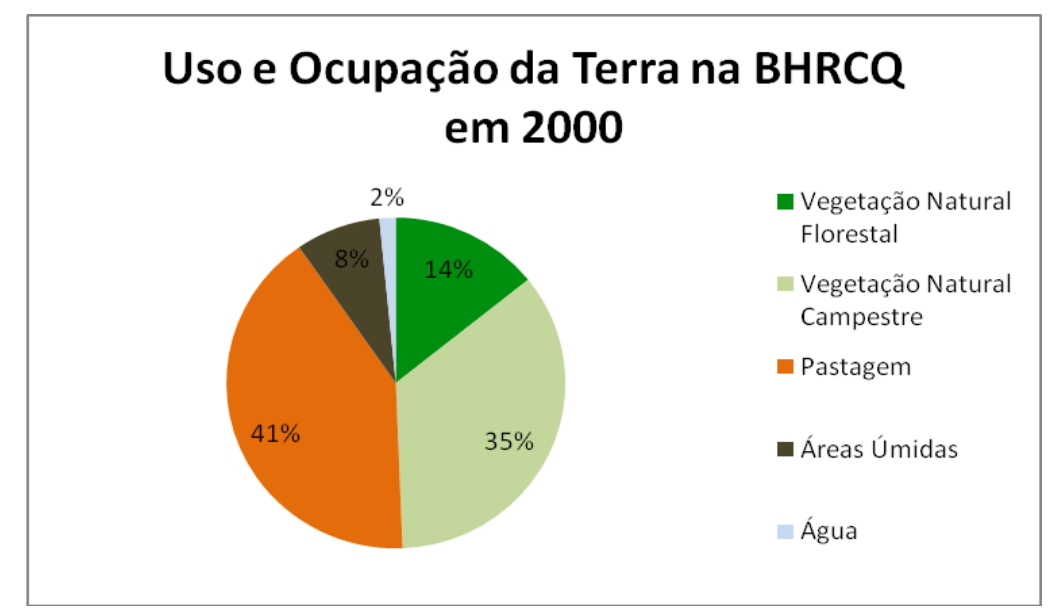

Gráfico 01: Uso e ocupação da terra na BHRCQ no ano de 2000.

Organização: BRAZ, A. M. 


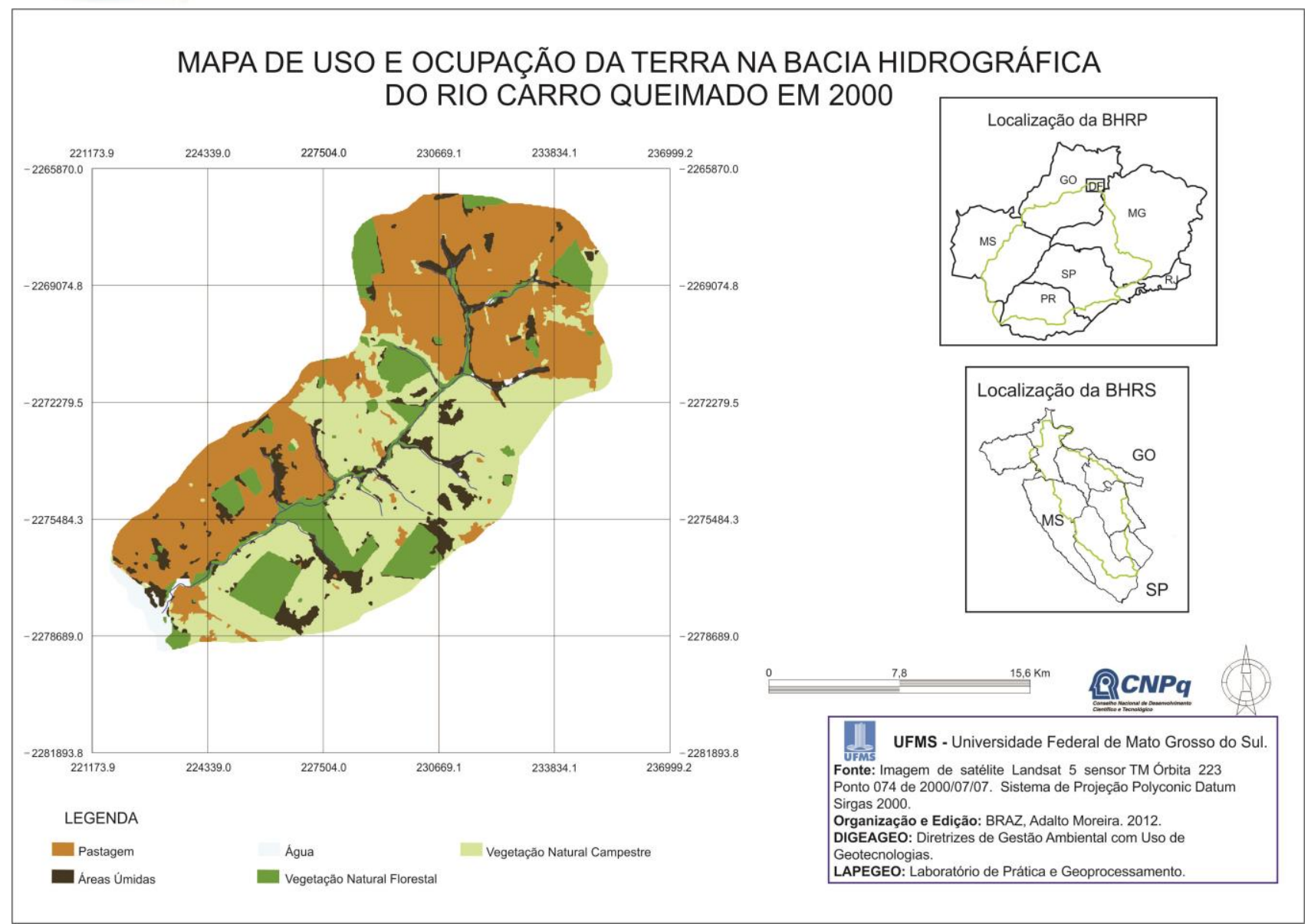

Posteriormente, o outro ano analisado foi de 2011, a análise apontou as mesmas cinco principais classes do uso e ocupação da terra e uma nova classe surgiu, a silvicultura, apresentando $15 \%$. Isso ocorre em função da necessidade de produção de eucaliptos na região, voltados à fabricação de celulose e papel, liderada por empresas como Fibria, Votorantim Celulose e Papel e Eldorado (em processo de instalação). Com a chegada de empresas fabricantes de celulose na região se tornou comum ver plantações de eucaliptos próximas a bacias hidrográficas, proporcionando uma mudança no cenário paisagístico do município. Observamos também o aumento da área Vegetação Natural Florestal, agora com $23 \%$. As classes Áreas Úmidas e Água também apresentaram números menores em relação ao ano de 2000, apresentando-se agora 2\% e 1\% respectivamente. A classe Vegetação Natural Campestre sofreu uma regressão significativa, apresentando-se no ano de 2011 com pouco menos da metade da porcentagem encontrada no gráfico do ano de 2000. Em 2011 essa classe apareceu com 11\%. A classe 
pastagem permanece sendo a principal classe de uso e ocupação na bacia, apresentando 48\%, havendo um pequeno aumento em relação ao ano de 2000.

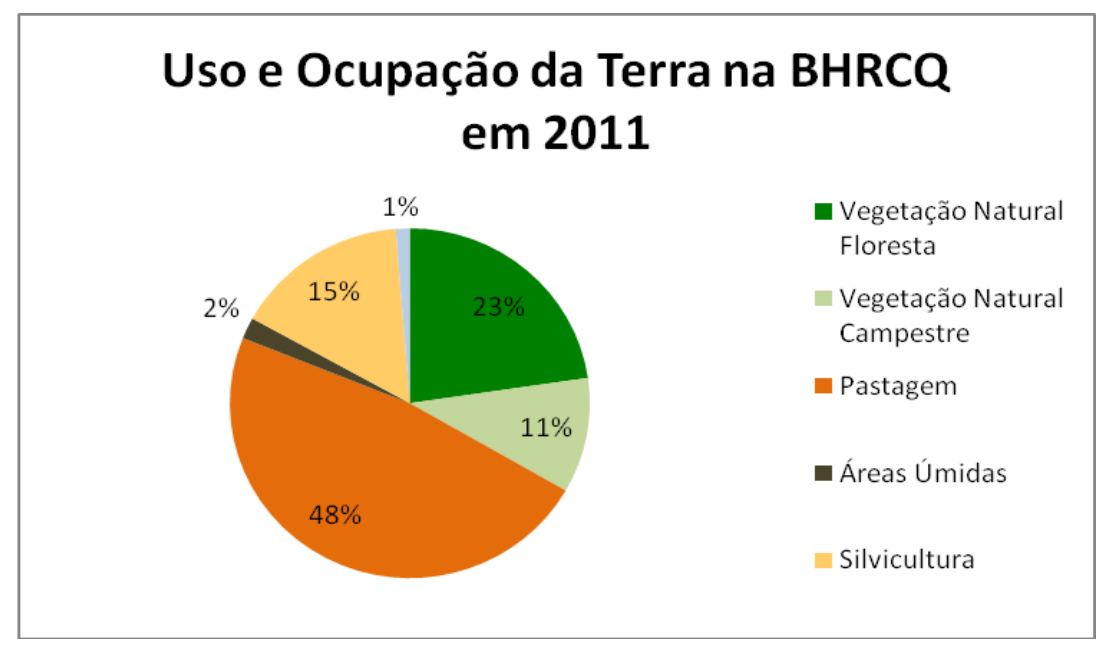

Gráfico 02: Uso e ocupação da terra na BHRCQ no ano de 2011.

Organização: BRAZ, A. M.

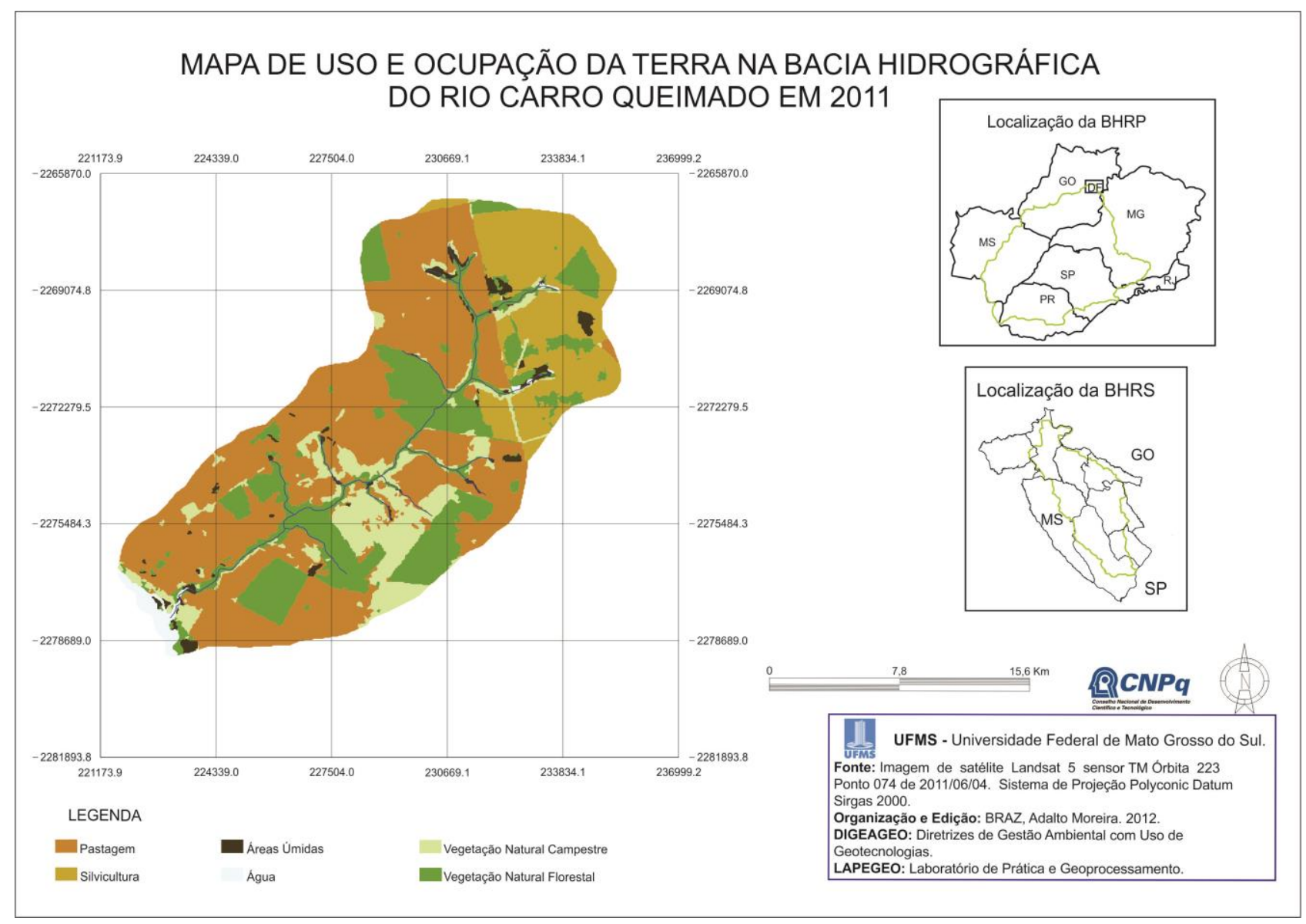


O diagnóstico foi feito na área através de checagens de campo e auxiliado com base na Matriz de Análise Ambiental para Bacias Hidrográficas. Foi utilizada a matriz em dois pontos, sendo um próximo à uma das nascentes da BHRCQ. No primeiro ponto analisado com o auxílio da matriz, foram identificadas alterações no ambiente como: introdução de flora e fauna exótica, modificação do habitat, alteração da cobertura superficial, controle do rio, pontes, estradas, cercas, erosão e ravinamento e assoreamento do canal. $O$ primeiro ponto foi analisado nas coordenadas $20^{\circ} 32^{\prime} 59^{\prime \prime} \mathrm{S}$ e $51^{\circ} 48^{\prime} 29^{\prime \prime} \mathrm{O}$.

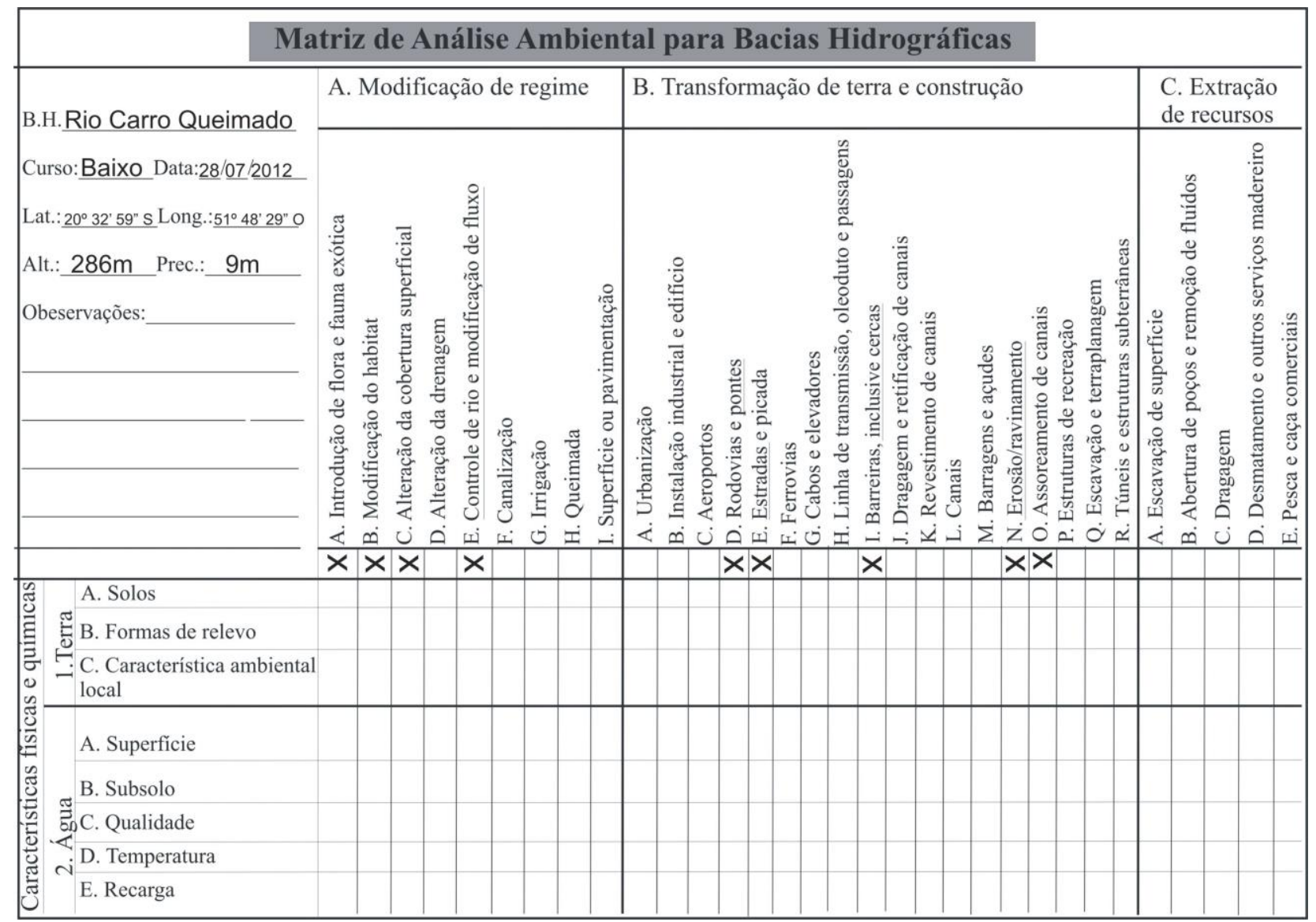

Quadro 03: Matriz de Análise Ambiental para Bacias Hidrográficas (conforme LAPEGEO, 2011. IZIPPATO, F. J.; MIRANDOLA, P. H).

O segundo ponto analisado se enquadra nas coordenadas $20^{\circ} 31^{\prime} 99^{\prime \prime} \mathrm{S}$ e $51^{\circ}$ 49' 24" O e foram identificadas nele, as seguintes alterações: modificação do habitat, alteração da cobertura superficial, controle do rio, canalização, estradas, cercas e assoreamento. Nos arredores do local também foram identificadas cercas atravessando o curso do rio, ausência de mata ciliar, acesso do gado à área de nascente e pisoteio do gado. 


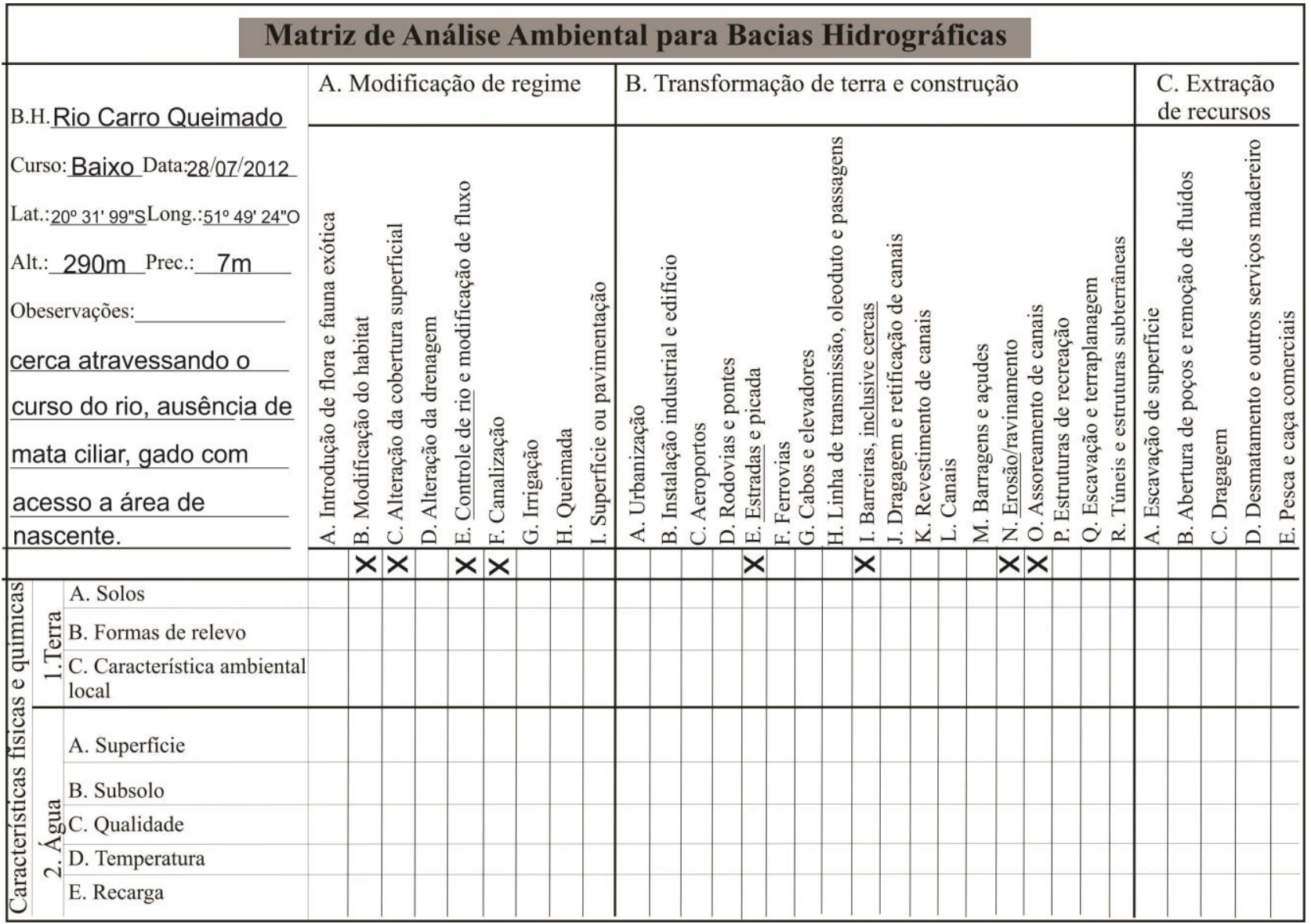

Quadro 04: Matriz de Análise Ambiental para Bacias Hidrográficas (conforme LAPEGEO, 2011. IZIPPATO, F. J.; MIRANDOLA, P. H).

Acompanhado das informações extraídas com a Matriz de Análise Ambiental para Bacias Hidrográficas, constatou-se as seguintes imagens: pisoteio do gado (Figura 1), eucaliptos próximos à áreas de nascente (Figura 2), ausência de mata ciliar em alguns trechos do rio e até mesmo em nascentes (Figura 3), cercas próximas à áreas de nascente - em uma determinada localidade, até passando em cima da área de nascente (Figura 4).

Os cenários de ambientes construídos ou transformados pela ação do homem ocupam a maior parte dos sistemas ambientais. $O$ homem transforma os espaços através da derrubadas de matas, da implantação de pastagens e cultivos, da construção de estradas, portos, aeroportos, represas, da retificação e canalização de curso d'água, da implantação de indústrias e áreas urbanas. (FLORENZANO, 2002 apud MIRANDOLA, 2006). 
O pisoteio do gado foi encontrado em algumas áreas da BHRCQ e até mesmo próximo às nascentes, deixando a área vulnerável à erosões, pois quando se permite o acesso de animais em áreas de nascentes Calheiros et al. (2004) argumentam que "o pisoteio torna a superfície do solo próximo às nascentes. Compactado, diminui sua capacidade de infiltração, ficando sujeito à erosão laminar e, consequentemente, provocando a contaminação da água por partículas do solo, podendo provocar até mesmo soterramento da nascente".

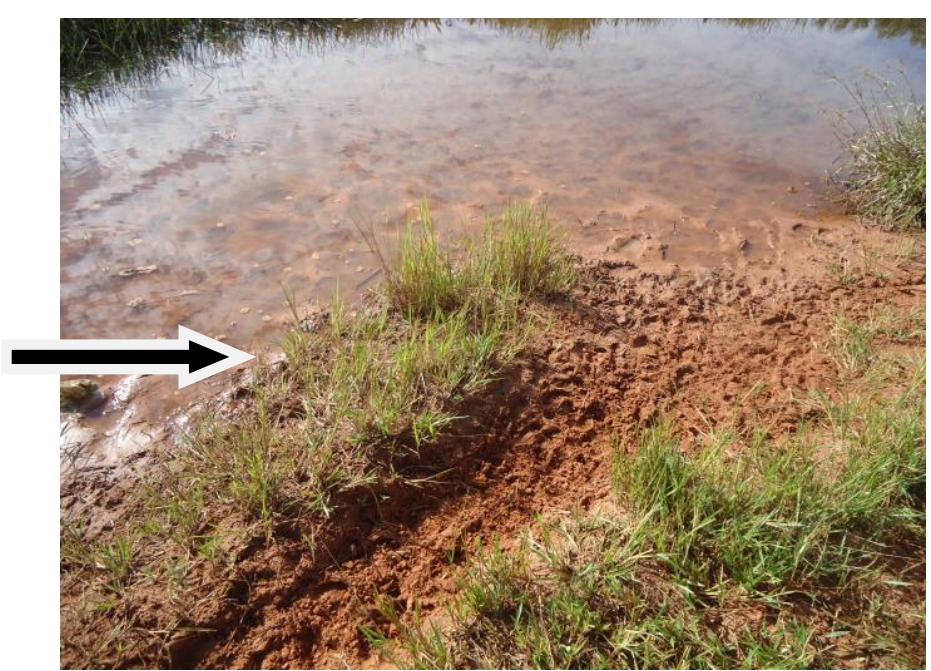

Figura 01 - Pisoteio do gado, nas margens do Rio Carro Queimado

Foto: Adalto, 2012

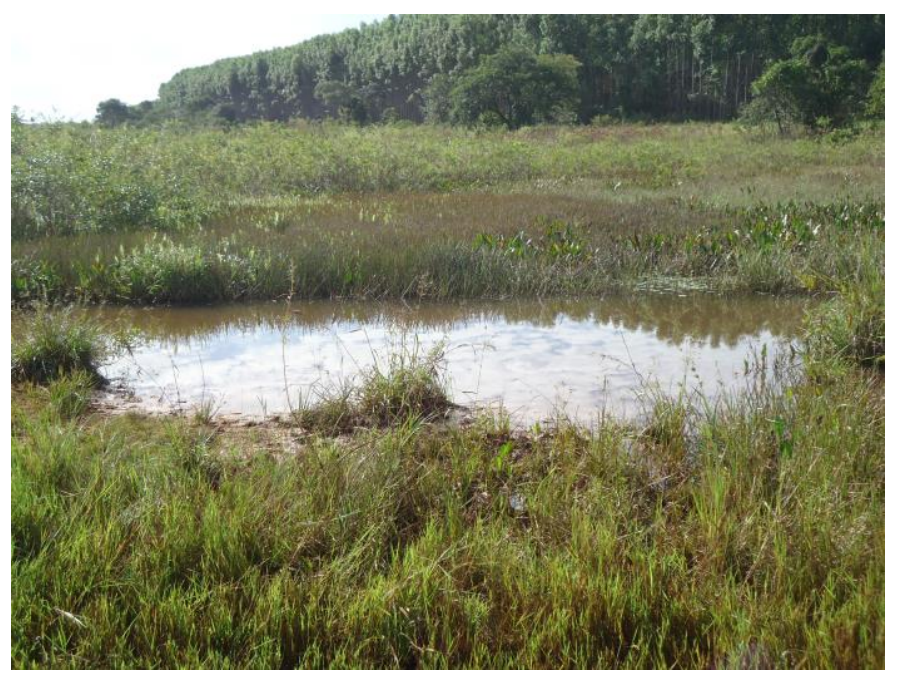

Figura 02 - Presença de Áreas de Eucalipto nas proximidades de nascentes do Rio Carro Queimado Foto: Adalto, 2012 


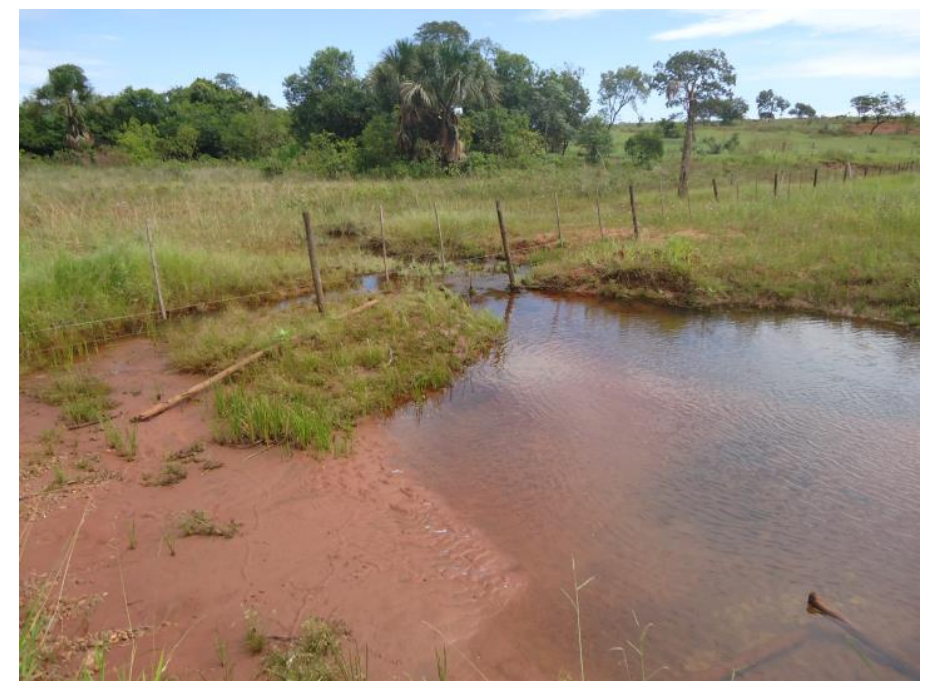

Figura 03 - Ausência de mata ciliar no Rio Carro Queimado

Foto: Adalto, 2012

\section{CONCLUSÃO}

Em um primeiro momento observamos o aumento de algumas classes, enquanto outras diminuíram, ou mesmo a classe Silvicultura, que no ano de 2000 não se faz presente na área, ou seja, o uso e ocupação da terra não se encontra da mesma forma, havendo mudanças significativas em sua dinâmica.

Quando aos métodos e procedimentos utilizados, confirmou-se sua eficácia, pois os dados da área foram processados e transformado em informações que podem subsidiar um posterior planejamento na área da BHRCQ. O mapa da área foi gerado com as classes temáticas presentes nos anos de 2000 e 2011, permitindo quantificar e avaliar a situação atual e as mudanças ocorridas no uso e ocupação da terra na bacia.

A Matriz de Análise Ambiental para Bacias Hidrográficas aplicada no Rio Carro Queimado apresentou modificações em determinadas áreas da bacia. O fator predominante nas modificações da paisagem é o antrópico, podendo provocar impactos ambientais em função de algumas atividades incorretas, como retirada de mata ciliar, ocupação incorreta em áreas de nascente ou próximas às margens do rio, plantações que avançam até as margens ou próximas à nascentes (lugares onde deveriam ser totalmente ocupados por matas ciliares), pavimentação que passam 


\section{Then Fórum Ambiental \\ da Alta Paulista

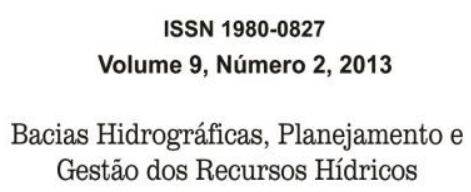

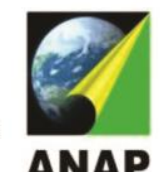

nas proximidades de áreas de nascente, acesso direto do gado ao canal, havendo pisoteio do mesmo.

Vale lembrar que o homem é um agente modificador dos ambientes naturais, ficando evidente, assim, suas modificações na área da BHRCQ, que carecendo de planejamento e organização de suas atividades de ocupação irregular na bacia. Portanto, segundo FERREIRA (2010) planejar significa elaborar planos de melhoria. Significa encontrar diretrizes para corrigir os espaços mal organizados e improdutivos. Significa encontrar meios e propiciar condições para interferir nos setores menos favoráveis de uma estrutura ou de uma conjuntura.

\section{REFERÊNCIAS}

BERTALANFFY, L. V. Teoria Geral dos Sistemas. Petrópolis: Vozes, 1975.

CHRISTOFOLETTI, Antonio. Modelagem de Sistemas Ambientais. 1 ed. São Paulo: Edgard Blücher, 1999.

CORREIA, V.R. de M. et al. Uma aplicação do sensoriamento remoto para a investigação de endemias urbanas. Cad. Saúde Pública, Rio de Janeiro, v.23, n.5.

FERREIRA, C.C. Uso de imagens de sensoriamento remoto para mapeamento do uso e ocupação da terra da Bacia Hidrográfica do Alto Sucuriú- MS-BR. II Simpósio Internacional da Cartografia na Geografia. São Paulo. 2010.

FLORENZANO, T. G. Imagens de Satélite para Estudos Ambientais. São Paulo: Oficina de textos, 2002.

FLORENZANO, Tereza Gallotti (org.). Geomorfologia: conceitos e tecnologias atuais. São Paulo: Oficina de Textos, 2008. 318p.

FLORENZANO, T. G. Iniciação em sensoriamento remoto. $2^{2}$ edição de imagens de satélite para estudos ambientais. São Paulo: Oficina de Textos, 2007.

MIRANDOLA-AVELINO, Patricia. Helena. Análise geo - ambiental multitemporal para fins de planejamento ambiental: um exemplo aplicado à bacia hidrográfica do Rio Cabaçal Mato Grosso - Brasil. Tese de Doutorado em Geografia do Programa de Pós Graduação em Geografia da Universidade Federal do Rio de Janeiro, 2006, $317 \mathrm{p}$. 